\title{
Alguns desafios do ensino de literatura na educação básica
}

Ana Cristina Coutinho Viegas ${ }^{a}$

\begin{abstract}
Resumo
O fortalecimento do ensino da literatura requer maior aproximação entre as pesquisas acadêmicas e as práticas pedagógicas. Essa aproximação implica, entre outros aspectos, questionamentos sobre a formação do professor e as estruturas curriculares na universidade. Em uma sociedade dominada por tecnologias visuais e pela cultura do entretenimento, é preciso rediscutir os objetivos de continuar a ensinar e estudar literatura. Este trabalho se propõe a discutir a importância da formação de professores como um dos caminhos fundamentais para que a escola obtenha êxito na tarefa desafiadora de inserir crianças e jovens no mundo da leitura literária.
\end{abstract}

Palavras-chave: Ensino de literatura. Educação Básica, Formação do professor. 
A escola brasileira do final do século XIX, movida por ideais nacionalistas, travou uma batalha para impor o estudo da literatura brasileira através de alterações nos programas de ensino e no material didático disponível.

Um estudo dos programas de ensino do século XIX do Colégio Pedro II, instituição fundada em 1837 e destinada a servir de modelo para o sistema educacional a ser implantado no país, mostra que apenas em 1892 o ensino de literatura passou a ser representado exclusivamente pela disciplina história da literatura nacional. Além do próprio nome da disciplina e da presença amplamente majoritária de tópicos da literatura brasileira no programa, outro sinal de sua institucionalização era o livro adotado, ou seja, a História da literatura brasileira, de Sílvio Romero (SOUZA, 2007).

Se, em fins do século XIX, a institucionalização do ensino de literatura se pautou no projeto de consolidação de uma identidade nacional e as histórias da literatura buscaram construir um cânone literário brasileiro, faz-se necessário discutir a relevância dos estudos literários para a formação linguística, estética e humana dos jovens do século XXI.

Em seu famoso ensaio O direito à literatura, de 1988, Antonio Candido defendeu a tese de que

[...] A distinção entre cultura popular e cultura erudita não deve servir para justificar e manter uma separação iníqua, como se do ponto de vista cultural a sociedade fosse dividida em esferas incomunicáveis, dando lugar a dois tipos incomunicáveis de fruidores. Uma sociedade justa pressupõe o respeito aos direitos humanos, e a fruição da arte e da literatura em todas as modalidades e em todos os níveis é um direito inalienável. (CANDIDO, 1995, p.262)

Duas décadas depois, em seu livro A literatura em perigo, o teórico Todorov (2009) reivindicou que o texto literário volte a ocupar o centro do ensino de literatura, enfatizando que a experiência da leitura deve preceder as análises críticas que adjetivam as obras e correm o risco de afastar o leitor.

No final do século $X X$, os estudos culturais e o avanço das novas tecnologias tornaram mais espinhosos os caminhos a serem trilhados pelos estudos literários, problematizando o corpus que constitui seu objeto de pesquisa e os valores que conferem a uma obra a sua qualidade literária. Ficou claro que 
as correntes formalistas e estruturalistas do século XX estavam intimamente ligadas à produção literária do período, ou seja, ao modernismo de autores como Joyce, Proust, Borges, Clarice Lispector, entre outros.

Concomitantemente às discussões e aos impasses teóricos, a Universidade precisa cumprir seu papel de formar professores, os quais, no espaço escolar, enfrentarão diferentes desafios na tentativa de fazer de seus alunos leitores de literatura, isto é, sujeitos críticos capazes de interagir com os textos literários ultrapassando os limites de uma leitura impressionista.

Do ponto de vista dos documentos oficiais, na segunda metade do século XX, a LDB n. 5692/71 dicotomizou a disciplina em Língua e Literatura. Essa divisão repercutiu na separação entre gramática, estudos literários e redação, modelo reproduzido nos livros didáticos do Ensino Médio até hoje. Além disso, os estudos literários continuam tendo como foco a historiografia da literatura brasileira, o que pode ser facilmente constatado nas coleções que compõem os guias de livros didáticos do PNLD (Programa Nacional do Livro Didático). Se considerarmos que grande parte dos professores da Educação Básica orientam suas aulas pelos livros didáticos, somos levados a concluir que a mudança de perspectiva teórica precisará acontecer nesse material a fim de que se efetive nas escolas.

Ainda do ponto de vista dos documentos oficiais, os Parâmetros Curriculares Nacionais situaram o texto literário entre os diferentes gêneros discursivos a serem lidos na escola. Tendo como referência a LDB n. 9394/96, os PCNs entendem o estudo da gramática como uma estratégia para a compreensão, a interpretação e a produção de textos e integram a literatura à área da leitura, colocando os gêneros literários lado a lado com gêneros jornalísticos, publicitários, entre outros. Sem apontar nenhum caminho para o letramento literário, dão a impressão de passar de um extremo a outro, ou seja, se tradicionalmente identificavam-se, na esfera escolar, gêneros e obras dignos de leitura, os PCNS tornaram todas as leituras equivalentes.

Antes de prosseguirmos nas reflexões sobre o ensino de literatura na contemporaneidade, cabem algumas considerações sobre dois conceitos anteriormente citados: o de gêneros do discurso e o de letramento. 
Quanto ao primeiro, os Parâmetros Curriculares apoiam-se no conhecido conceito bakhtiniano de gênero do discurso (BAKHTIN, 2011). Bakhtin chama atenção para o fato de que

[...] a questão geral dos gêneros nunca foi verdadeiramente colocada. Estudavam-se - e mais que tudo - os gêneros literários. Mas da Antiguidade aos nossos dias eles foram estudados num corte da sua especificidade artístico-literária, nas distinções diferenciais entre eles (no âmbito da literatura) e não como determinados tipos de enunciados, que são diferentes de outros tipos mas têm com estes uma natureza verbal (linguística) comum. (BAKHTIN, 2011, p. 262)

Apesar de equiparar os gêneros literários aos demais gêneros do discurso por sua "natureza verbal", o autor salienta que

[...] a réplica do diálogo cotidiano ou da carta no romance, ao manterem a sua forma e o significado cotidianos apenas no plano do conteúdo romanesco, integram a realidade concreta apenas através do conjunto do romance, ou seja, como acontecimento artístico-literário e não da vida cotidiana. (BAKHTIN, 2011, p. 264)

Não pretendemos estender ou aprofundar as discussões a respeito dos estudos bakhtinianos sobre literatura, o que fugiria ao propósito deste artigo. Basta ressaltar, contudo, que, mesmo em texto que não se debruça especificamente sobre questões literárias, o teórico já tangencia especificidades dos gêneros literários.

Sobre o conceito de letramento, de acordo com Angela Kleiman, "podemos definir hoje o letramento como um conjunto de práticas sociais que usam a escrita enquanto sistema simbólico e enquanto tecnologia em contextos específicos para objetivos específicos" (KLEIMAN, 1995, p. 19). Partindo de pesquisas da autora sobre letramento e também de outras pesquisas provenientes da Linguística as quais se dedicam a estudar o assunto, faz-se necessário avaliar de que modo o conceito de letramento é pertinente para o estudo das práticas da leitura literária. A princípio, se considerarmos a literatura como um tipo de atividade social e cultural que emprega a escrita, o conceito de letramento mostra-se bastante produtivo para pensarmos o sistema literário em seus aspectos de produção, recepção e circulação, o que inclui também o ensino da literatura. 
Os Parâmetros direcionados ao Ensino Médio organizam as disciplinas em grandes áreas. A área denominada "Linguagens, códigos e suas tecnologias" inclui Língua Portuguesa, Línguas Estrangeiras, Educação Física, Artes e Informática, pressupondo um trabalho interdisciplinar. Nesse caso, a literatura poderia ser trabalhada em cada uma dessas áreas como manifestação linguística, artística e na sua relação com as linguagens do corpo e da informática. Esse viés inter ou multidisciplinar não pode suprir o trabalho feito especificamente pelo professor licenciado em Letras, aquele profissional com autoridade para discutir questões teóricas dos estudos literários e pôr em prática atividades de formação do leitor do texto literário.

Tomando para si as rédeas da discussão sobre o ensino de literatura na Educação Básica, os professores responsáveis pelo capítulo dedicado à literatura nas Orientações Curriculares para o Ensino Médio publicadas pelo MEC em 2006 chamam atenção para essas especificidades do texto literário. Partindo do conceito de letramento de Magda Soares - "estado ou condição de quem não apenas sabe ler e escrever, mas cultiva e exerce as práticas sociais da escrita" (SOARES, 2004, p. 47) -, asseguram que o letramento literário pressupõe que o aluno não apenas seja capaz de ler o poema, o drama ou a narrativa literária, mas também se aproprie efetivamente desses textos por meio da "experiência estética", embora não nos detenhamos neste artigo em considerações sobre o termo. Se, por um lado, não podemos confundir "prazer estético", "fruição", com divertimento, por outro, sabemos da complexidade teórica para definir tal experiência do leitor. Mais uma das muitas complexidades que envolvem os estudos literários.

Ainda segundo as Orientações Curriculares, o ensino de literatura nas séries do Ensino Fundamental se caracteriza por uma formação menos sistemática e mais aberta do ponto de vista das escolhas dos textos pelos professores, visto que há uma mistura indistinta entre a chamada literatura infanto-juvenil e a literatura considerada canônica. Apenas no Ensino Médio ocorre a sistematização do ensino de literatura e essa se dá pela perspectiva historiográfica.

É importante lembrar que há uma ruptura na passagem do Ensino Fundamental para o Ensino Médio e essa não se restringe à sistematização dos conteúdos, mas atinge também 
a própria escolha dos textos a serem lidos. A formação do leitor no Ensino Fundamental está repleta de ficções de ação e de aventuras, além de um grande número de crônicas de escritores contemporâneos. Na primeira série do Ensino Médio, à medida que o ensino de literatura está pautado em modelo historiográfico, o adolescente já se depara com textos barrocos e árcades. Primeiramente, é preciso que ele perceba a relevância dessa leitura para um jovem do século XXI. Essa relevância talvez seja capaz de justificar todo esforço empreendido para o entendimento desses textos.

\section{Uma experiência com a formação de professores}

As discussões sobre perspectivas teóricas, a busca de novas metodologias e a formação do professor de literatura evidenciam que a ponte entre a Universidade e a Escola Básica precisa se fortalecer. Os estudiosos de literatura precisam levar em conta, em suas pesquisas, as experiências com seu objeto de estudo nesse espaço de circulação social e formação do leitor que é a escola.

O livro de Cyana Leahy-Dios Educação literária como metáfora social, publicado em 1990, trouxe importantes contribuições para uma discussão que se tornou urgente diante das dificuldades generalizadas e do desinteresse dos alunos de nível médio pela leitura do texto literário. Segundo a própria autora, sua pesquisa tenta determinar os objetivos de ensinar e estudar literatura no mundo atual.

Ainda de acordo com a autora, a educação literária é o locus ideal dos discursos pós-estruturalistas, feministas, pós-colonialistas, entretanto esse aspecto ainda é muito pouco explorado em nossas salas de aula da Educação Básica, que deveriam se caracterizar como espaços de convivência democrática com a diversidade que compõe o corpo discente.

A leitura crítica e competente é fundamental para a formação emocional, ética e política dos jovens. Para isso, requer a interseção dos estudos acadêmicos com uma pedagogia crítica que invista mais na formação do leitor do que no caráter informativo que vem predominando com o ensino centrado em caracterizações de escolas literárias e na leitura de fragmentos de textos. É comum professores da Educação Básica trabalharem em escolas que enfatizam a memorização de conteúdos 
O levantamento foi feito no Campus Engenho Novo II, sob a supervisão da bibliotecária Marta Regina de Jesus. A relação completa por ordem alfabética do primeiro nome dos autores é composta pelos seguintes títulos: $O$ auto da compadecida (Ariano Suassuna), Crônicas de Nárnia (C.S.Lewis), São Bernardo (Graciliano Ramos), Diário de um banana (Jeff Kinney), Harry Potter e a pedra filosofal (J.K.Rowling), Clara dos anjos (Lima Barreto), Mar de monstros (R. Riordan), A dança da morte (Stephen King), A escolha dos três (Stephen King), A torre negra (Stephen King), Ele disse, ela disse (Thalita Rebouças), além de gibis da Turma da Mônica, de Maurício de Souza. e a passividade dos alunos. Os professores de Literatura não constituem exceção nesse caso.

A própria LDB 9.394/96, diretriz dos Parâmetros Curriculares Nacionais para o Ensino Médio, afirma que uma das finalidades do ensino na etapa final da Educação Básica vem a ser "o aprimoramento do educando como pessoa humana, incluindo a formação ética e o desenvolvimento da autonomia intelectual e do pensamento crítico" (BRASIL, LDB 9.394/96, Seção IV, Art. $35^{\circ}$ ). É inegável a contribuição da literatura para esse processo.

Por outro lado, não resta dúvida de que a escola tem obtido muito pouco sucesso no que se refere à formação do chamado gosto literário, à sensibilização para o valor estético das obras.

Levantamento feito em 2011 pelos bibliotecários do Colégio Pedro II mostra que os títulos mais procurados pelos adolescentes encontram-se entre os clássicos cobrados pelos professores e os chamados best-seller ${ }^{1}$.

A lista dos livros mais procurados pelos alunos do Colégio Pedro II, assim como as listas dos mais vendidos apresentadas nos jornais e revistas levam a reflexões como a proposta pelo escritor Cristóvão Tezza:

Dos anos 70 em diante, começou a produção em série de literatura escolar, narrativas produzidas objetivamente para a sala de aula, com folhas de perguntas e respostas ao final do livro, o que coincidiu com a grande expansão da base escolar brasileira. Um estudo talvez estabelecesse a relação, se houver, entre a literatura escolar que vem sendo consumida há mais de trinta anos por crianças e jovens em sala de aula e as listas de best- sellers comprados por adultos nos dias de hoje no Brasil, mas é preciso evitar uma interpretação chapada, porque as variáveis são muitas. (TEZZA, 2012, p. 178)

Sabe-se que a lógica da indústria se impõe cada vez mais no campo cultural. Se, por um lado, a escola não está conseguindo formar leitores refinados para os textos literários, por outro, o próprio mercado poderia estar formando leitores. Sendo assim, esses leitores passariam da leitura dos best-sellers infantis e juvenis para a leitura dos best-sellers para adultos. Como ressalta o próprio Tezza, não é tão simples estabelecer essas relações. Pesquisas precisam comprová-las ou refutá-las. 
A formação do professor e o livro didático constituem os dois pontos centrais para a dinamização do ensino de literatura. Neste artigo, deter-nos-emos no primeiro, levando em conta a formação inicial na sua graduação em Letras e, principalmente, a formação continuada.

A reforma curricular está em pauta nos cursos de licenciatura brasileiros, os quais têm-se envolvido em difíceis deliberações sobre o que a preparação de professores deve incluir ou excluir, ou melhor, como preparar novos professores que possam responder às necessidades das comunidades de alunos. De qualquer modo, seria muito pretensioso acreditar que os professores dos cursos de licenciatura podem identificar a priori tudo que os futuros professores precisariam saber para ter sucesso com a grande variedade de alunos com os quais trabalharão e com os diferentes ambientes em que exercerão a sua prática. $\mathrm{O}$ conhecimento contextual leva os professores para além das estratégias da prática de ensino, obrigando-os a analisar as necessidades dos alunos dentro de vários contextos socioculturais, econômicos e políticos.

No artigo Letramento e suas implicações para o uso da língua materna, Angela Kleiman afirma que

A prática social como ponto de partida e de chegada implica [...] uma pergunta estruturante do planejamento das aulas diferente da tradicional, que está centrada nos conteúdos curriculares: "qual a sequência mais adequada de apresentação dos conteúdos?" [...] Quando o conteúdo (qualquer que seja) não constitui o elemento estruturante do currículo, a pergunta que orienta o planejamento das atividades didáticas deixa de ser "qual é a sequência mais adequada de apresentação dos conteúdos linguísticos, textuais ou enunciativos?" porque o professor, com conhecimento pleno dos conteúdos do ciclo e ciente de sua importância no processo escolar, passa então a fazer uma pergunta de ordem sócio-histórica e cultural: "quais os textos significativos para o aluno e sua comunidade?" (KLEIMAN, 2007, p. 6)

Dentro dessa perspectiva, não é possível limitar o ensino da literatura ou de qualquer outro conteúdo à sequência apresentada pelo livro didático. Mais do que isso, é necessário um trabalho de equipe para que se torne viável replanejar conteúdos e estratégias, além de preparar material didático que atenda a esse novo planejamento. 
No programa de formação continuada do qual participo há três anos, os professores são oriundos da rede estadual do Rio de Janeiro e de alguns municípios desse estado. Levando em conta o fato de o ensino sistematizado da literatura só acontecer no Ensino Médio e também o fato de o município se responsabilizar apenas pelo Ensino Fundamental, esta pesquisa se deterá nos professores de Português ligados à SEEDUC que vêm participando do programa.

O Currículo Mínimo elaborado pela Secretaria de Estado de Educação do Rio de Janeiro serve como referência a todas as escolas da rede estadual e tem por objetivo garantir uma base comum a todas elas. Para isso, apresenta as competências e as habilidades que devem estar contempladas nos planos de curso e nos planos de aula. Esse currículo que orienta as atividades pedagógicas dos professores com os quais convivo na formação continuada apresenta os conteúdos de literatura para o Ensino Médio de acordo com uma perspectiva historiográfica, a qual tem início na primeira série com a chamada Literatura de informação, os textos jesuíticos, a poesia barroca e assim sucessivamente (Currículo Mínimo -. Língua Portuguesa e Literatura. Disponível em http://www.conexaoprofessor.rj.gov. br/c urriculo_identificacao.asp (acessado em 20 de jul. de 2014).

São reclamações constantes desses professores a grande quantidade de conteúdo a ser trabalhado em uma única série, a dificuldade dos seus alunos na leitura dos textos literários, a falta de recursos para a produção de material didático e a inexistência de um trabalho em equipe disciplinar ou interdisciplinar, para que possam ser discutidas e avaliadas as experiências nas turmas de suas respectivas escolas.

Anualmente um grupo de professores participa do Programa, que tem duração de sete meses e cujas atividades acontecem no espaço do Colégio Pedro II no Rio de Janeiro. Além de atividades com as turmas de Ensino Fundamental e Médio do Colégio, esses professores, denominados residentes, participam de oficinas interdisciplinares e de grupos de leitura dentro de suas respectivas disciplinas. Ao final do Programa, precisam defender um Produto Final, que seja resultado das observações, da leitura e da troca de ideias e material didático realizada com seus Supervisores, que são professores do Colégio Pedro II. Na avaliação final do Programa, um dos pontos positivos recorrentes é a troca pedagógica, que revigora, 
fortalece a autoestima e, em alguns casos, leva o professor de volta aos bancos da universidade para fazer cursos de Pós-Graduação strictu sensu.

O termo "residente" foi tomado de empréstimo à Medicina e a ideia é, assim como na área médica, aproximar a teoria e a prática. O objetivo é contribuir para a formação de professores que atuam em escolas públicas mais desafiadoras. Formar não é apresentar um modelo a ser seguido, e sim orientar o professor, agente no processo de sua própria formação, no sentido de refletir sobre sua prática, buscar ações mais eficazes com seus alunos e construir sua identidade como um profissional.

No caso específico do ensino de literatura, como destaca Magda Soares, no ensaio A escolarização da leitura literária,

[...] o que se pode é distinguir entre uma escolarização adequada da literatura - aquela que conduza mais eficazmente às práticas de leitura que ocorrem no contexto social e às atitudes e valores que correspondem ao ideal de leitor que se quer formar - e uma escolarização inadequada, errônea, prejudicial da literatura - aquela que antes afasta que aproxima de práticas sociais de leitura, aquela que desenvolve resistência ou aversão à leitura. (SOARES, 2011, p.25)

Quando a literatura entra nos domínios escolares, a sua escolarização é inevitável. Isso não impede, porém, que sejam criadas alternativas para se atingirem resultados satisfatórios na formação de leitores. Os professores precisam estar atentos e observar práticas de letramento literário que se dão além do espaço escolar, como adaptações de textos literários para a televisão e o cinema. Enfim é preciso mostrar para o jovem que a literatura está viva. Para isso, os professores também precisam reavaliar constantemente as suas práticas.

\section{Considerações finais}

Em meio a tantas inovações industriais e tecnológicas, é preciso permanecer atento ao processo de mecanização do ser humano. A literatura cumpre papel fundamental no sentido de nossa humanização. Se o mundo capitalista tem como valor a utilidade, a literatura, bem como as outras artes, se constrói no desperdício do qual o ser humano necessita.

Na sala de aula da Educação Básica, não se acredita mais que testes, provas ou qualquer outro tipo semelhante 
de avaliação contribua para a empreitada de formar leitores de literatura. Atividades como rodas de leitura, contação de histórias, leituras dramatizadas de poemas entre tantas outras realizadas no espaço escolar, sob a orientação dos professores de literatura, têm-se mostrado muito mais eficazes, principalmente no que se refere aos textos clássicos, os quais exigem um leitor mais sofisticado.

Ainda é cedo para termos avaliações mais precisas do Programa de Residência Docente no Colégio Pedro II. Entre nossos objetivos, no entanto, estão a realização de estudos acerca do letramento literário e da formação dos professores de literatura. Esses estudos precisam tomar por base o que os próprios professores entendem como objetivos para as práticas de leitura na escola, já que esses objetivos nortearão suas ações. Além disso, faz-se necessário realizar pesquisas constantes sobre o impacto de programas como esse nas turmas desses professores.

Por fim, o principal argumento para se continuar a ensinar literatura é o de que a leitura literária, como nos lembra Antonio Candido, é um direito de todos desde a infância. Negar o contato com qualquer tipo de representação artístico-literária é privar o jovem de exercer sua humanidade plenamente. Políticas públicas são fundamentais para a garantia desse direito. Vale lembrar, entretanto, que qualquer iniciativa que desconsidere o investimento no professor se mostrará infrutífera.

\section{REFERÊNCIAS}

BAKHTIN, Mikhail. Estética da criação verbal. Trad. Paulo Bezerra. 6ed. São Paulo: WMF Martins Fontes, 2011.

BRASIL. Lei de Diretrizes e Bases 9394/96. Brasília, 1996.

BRASIL. Lei de Diretrizes e Bases 5692/71. Brasília, 1971.

CANDIDO, Antonio. O direito à literatura. In: . Vários escritos. 3 ed. São Paulo: Duas Cidades, 1995. p. 235- 265.

LEAHY-DIOS, Cyana. Educação literária como metáfora social: desvios e rumos. 2 ed. São Paulo: Martins Fontes, 2004

KLEIMAN, A. B. Letramento e suas implicações para o ensino de língua materna. Signo, Santa Cruz do Sul, v. 32, n. 53, p. 1-25, dez. 2007. 
Modelos de letramento e as práticas de alfabetização na escola. In: KLEIMAN, A. B. (org.) Os significados do letramento: uma nova perspectiva sobre a prática social da escrita. Campinas: Mercado de Letras, 1995.

MEC/SECRETARIA DE EDUCAÇÃO MÉDIA E TECNOLÓGICA. Parâmetros curriculares nacionais. Ensino Médio. Brasília, 1999.

MEC/SECRETARIA DE EDUCAÇÃO BÁSICA. Orientações curriculares para o Ensino Médio. Brasília, 2006.

SECRETARIA DE ESTADO DE EDUCAÇÃO. Currículo Mínimo -. Língua Portuguesa e Literatura. Rio de Janeiro. Disponível em http://www.conexaoprofessor.rj.gov.br/c urriculo_ identificacao.asp (acessado em 20 de jul. de 2014).

SOARES, Magda. Letramento: um tema em três gêneros. Belo Horizonte, Autêntica, 2004.

SOARES, Magda. A escolarização da leitura literária. In: EVANGELISTA, Aracy Alves Martins, BRANDÃO, Heliana Maria Brina \& MACHADO, Maria Zélia Versiani (orgs.). Escolarização da leitura literária - o jogo do livro infantil e juvenil. 2ed. Belo Horizonte: Autêntica, 2011.

SOUZA, Roberto Acízelo de. Introdução à historiografia da literatura brasileira. Rio de Janeiro: EdUERJ, 2007

TEZZA, Cristóvão. O espírito da prosa - uma autobiografia literária. Rio de Janeiro: Record, 2012

TODOROV, Tzvetan. A literatura em perigo. Rio de Janeiro: Difel, 2009. 


\section{Abstract}

\section{Some challenging tasks of teaching literature} in elementary education

The encouragement to the teaching of literature requires closer contact between the academic research and the pedagogical practices at schools. It takes us in to questioning on two different areas: teacher education and curricular structures. It is necessary to discuss the objectives of teaching and studying literature. This work aims at discussing the importance of teachers education for the challenging task of inserting sucessfully children and youngsters in the world of reading literature.

Keywords: Teaching literature. Elementary education. Teacher education. 